\title{
Complement evasion by Bordetella pertussis: implications for improving current vaccines
}

\author{
Ilse Jongerius • Tim J. Schuijt • Frits R. Mooi • \\ Elena Pinelli
}

Received: 11 December 2014 / Revised: 19 January 2015 / Accepted: 27 January 2015 / Published online: 18 February 2015

(C) The Author(s) 2015. This article is published with open access at Springerlink.com

\begin{abstract}
Bordetella pertussis causes whooping cough or pertussis, a highly contagious disease of the respiratory tract. Despite high vaccination coverage, reported cases of pertussis are rising worldwide and it has become clear that the current vaccines must be improved. In addition to the well-known protective role of antibodies and $\mathrm{T}$ cells during $B$. pertussis infection, innate immune responses such as the complement system play an essential role in B. pertussis killing. In order to evade this complement activation and colonize the human host, $B$. pertussis expresses several molecules that inhibit complement activation. Interestingly, one of the known complement evasion proteins, autotransporter Vag8, is highly expressed in the recently emerged B. pertussis isolates. Here, we describe the current knowledge on how $B$. pertussis evades complement-mediated killing. In addition, we compare this to complement evasion strategies used by other bacterial species. Finally, we discuss the consequences of complement evasion by $B$. pertussis on adaptive immunity and how identification of the bacterial molecules and the mechanisms involved in complement evasion might help improve pertussis vaccines.
\end{abstract}

Ilse Jongerius and Tim J. Schuijt contributed equally to this work.

I. Jongerius $\cdot$ T. J. Schuijt $•$ F. R. Mooi $\cdot$ E. Pinelli $(\bowtie)$

Centre for Infectious Disease Control, National Institute for Public

Health and the Environment, Antonie van Leeuwenhoeklaan 9,

P.O. Box 1, 3720 BA Bilthoven, The Netherlands

e-mail: elena.pinelli.ortiz@rivm.nl

Present Address:

I. Jongerius

Department of Medical Microbiology, University Medical Center

Utrecht, Heidelberglaan 100, 3584 CX Utrecht, The Netherlands

Present Address:

T. J. Schuijt

Department of Clinical Chemistry, Hematology and Immunology,

Diakonessenhuis, Bosboomstraat 1, 3582

KE Utrecht, The Netherlands
Keywords Complement $\cdot$ Bordetella pertussis . Innate immunity $\cdot$ Evasion $\cdot$ Vaccine

\section{Introduction}

The Gram-negative bacterium Bordetella pertussis causes pertussis or whooping cough, a highly contagious disease of the respiratory tract of humans. $B$. pertussis is primarily transmitted via direct contact or inhalation of airborne droplets expelled by infected individuals while coughing $[1,2]$. Upon infection, the bacteria attach to ciliated epithelium of the upper respiratory tract where they multiply and express various virulence factors that favor colonization (Fig. 1) [2, 3]. These virulence factors include, e.g., membrane-bound molecules involved in adherence to the ciliated cells, secreted toxins, and proteins that affect complement-mediated killing. Frequently associated complications of pertussis are pneumonia, otitis media, seizures, and (brain) hemorrhages [4]. Pertussis was a leading cause of infant death before the introduction of the whole-cell pertussis (wP) vaccines in the 1950s. Due to side effects of the wP vaccine, acellular pertussis $(\mathrm{aP})$ vaccines were introduced in the late 1990s [5]. Despite high vaccination coverage, reported cases of pertussis have been increasing over the past three decades [6, 7]. Possible explanations for the re-emergence of pertussis are the limited duration (waning) of aP vaccine-induced immunity and pathogen adaptation. Other influencing factors may be the increased awareness of disease and better diagnostic tools for detection of pertussis $[6,8,9]$.

To establish colonization and infection, pathogens have developed various mechanisms to evade host immune responses including the complement system [10]. B. pertussis is not an exception to this phenomenon. Here, we review what is known about the interactions between $B$. pertussis and the 


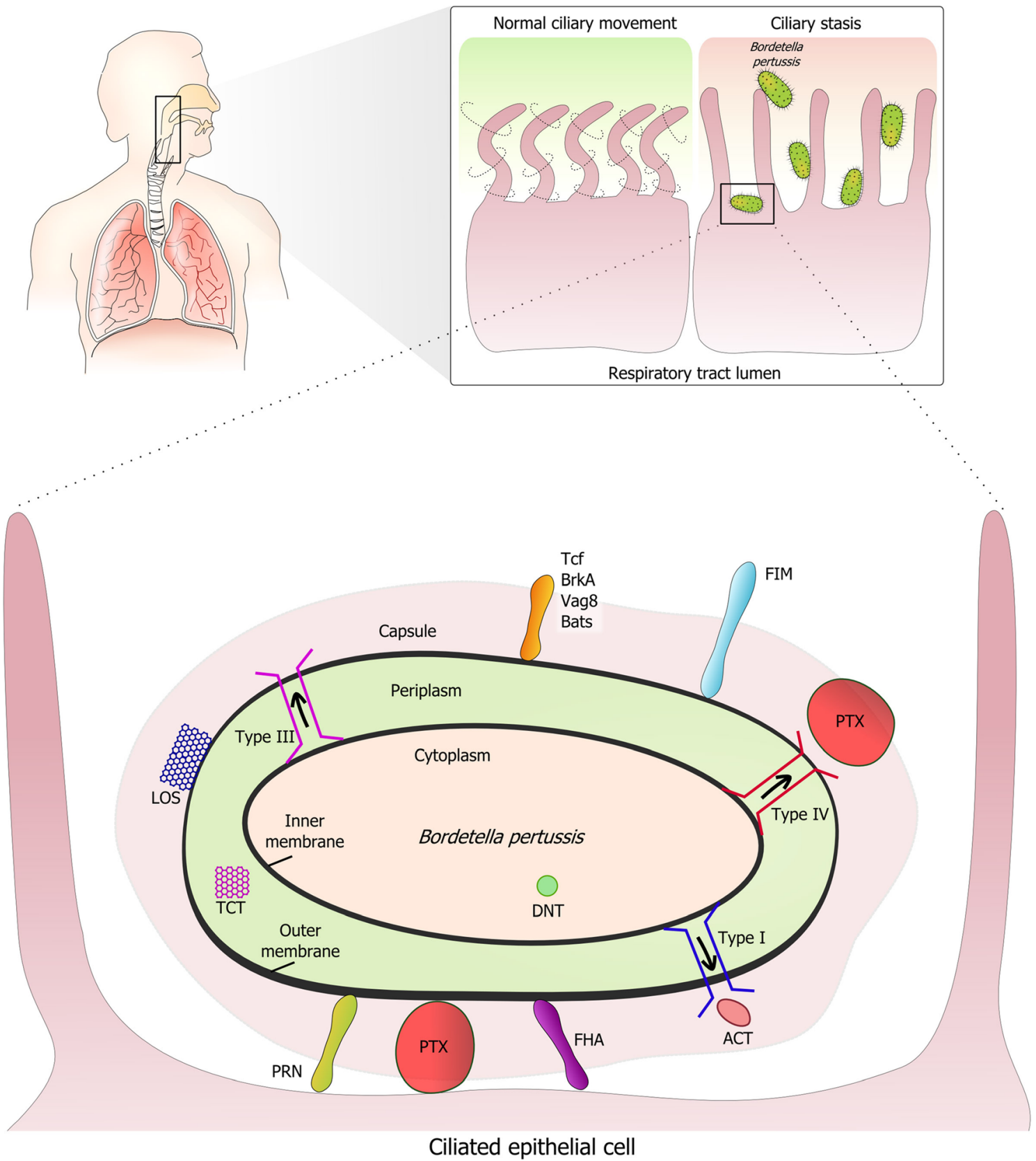

Fig. 1 Interaction of $B$. pertussis with mucosal surfaces. The Gramnegative bacterium $B$. pertussis interacts with ciliated epithelium in the respiratory tract. Cilia are found in the trachea, bronchi, and bronchioles and move continuously to keep the airway free of mucus-trapped microorganisms and dust. A number of $B$. pertussis proteins have been implicated in adherence to host receptors, including pertactin (Prn), cell-bound pertussis toxin (Ptx), filamentous hemagglutinin (FHA), fimbriae (Fim), tracheal colonization factor A (TcfA), Bordetella resistance to killing protein A (BrkA), the autotransporter Vag8, and other Bordetella

complement system and how this pathogen evades complement-mediated killing. In addition, we discuss how identification of the molecules and the mechanisms involved in complement evasion might help to improve the current $B$. pertussis vaccines. autotransporters (Bats). Ptx and adenylate cyclase toxin (ACT) are toxic for host cells including phagocytes. Bordetella dermonecrotic toxin (DNT) induces vasoconstriction in vitro. B. pertussis contains lipooligosaccharide (LOS, or endotoxin) in its outer membrane. Type I, III, and IV secretion systems are indicated in red, blue, and pink, respectively. Ciliostasis is induced by tracheal cytotoxin (TCT) and may induce bouts of intense coughing in whooping cough patients in order to remove accumulated mucus

\section{The role of complement in the host's defense against $B$. pertussis}

The human complement system serves as the first line of defense against microorganisms. The complement cascade can 
be activated via three different pathways: the classical $(\mathrm{CP})$, lectin (LP), and/or the alternative pathway (AP) (Fig. 2). Activation of any of the three pathways results in cleavage of $\mathrm{C} 3$ by $\mathrm{C} 3$ convertases which in turn leads to opsonization of bacteria with $\mathrm{C} 3 \mathrm{~b}$. C3b deposition greatly enhances bacterial uptake by phagocytic cells and can form a bridge between the innate and adaptive immunity $[11,12]$. In addition, C3b deposition on the bacterial surface leads to formation of $\mathrm{C} 5$ convertases which cleave $\mathrm{C} 5$ into the strong chemoattractant $\mathrm{C} 5 \mathrm{a}$ and $\mathrm{C} 5 \mathrm{~b}$, which in turn initiates the formation of the membrane attack complex (MAC) that can lyse Gramnegative bacteria [13]. To prevent damage to human cells, the complement system is strictly regulated and several complement regulatory proteins are described that can inhibit the $\mathrm{CP}$, LP, or AP [14]. Complement is not only present in the blood, but also on healthy human mucosal surfaces of the upper respiratory tract and the lungs. Moreover, almost all cells in the human body can produce complement proteins (reviewed in [15]). Therefore, complement can interfere with successful colonization and persistence of bacteria in the upper respiratory tract and the lung [16-18].

In addition to direct killing of invading microbes, complement activation is also involved in other biological processes of the human body [14] including the development and modulation of adaptive immune responses. Although it has long been acknowledged that complement plays a role in regulating B cell immunity [19], it has only recently become clear that complement is also involved in inducing and directing $\mathrm{T}$ cell responses [20]. This activation can occur through direct modulation of the T cells themselves, or indirect activation through alteration of mainly antigen presenting cells [21-23]. Furthermore, it has been shown that complement receptor-mediated signaling can act in synergy with different innate receptors such as Toll-like receptors, which promotes for example,

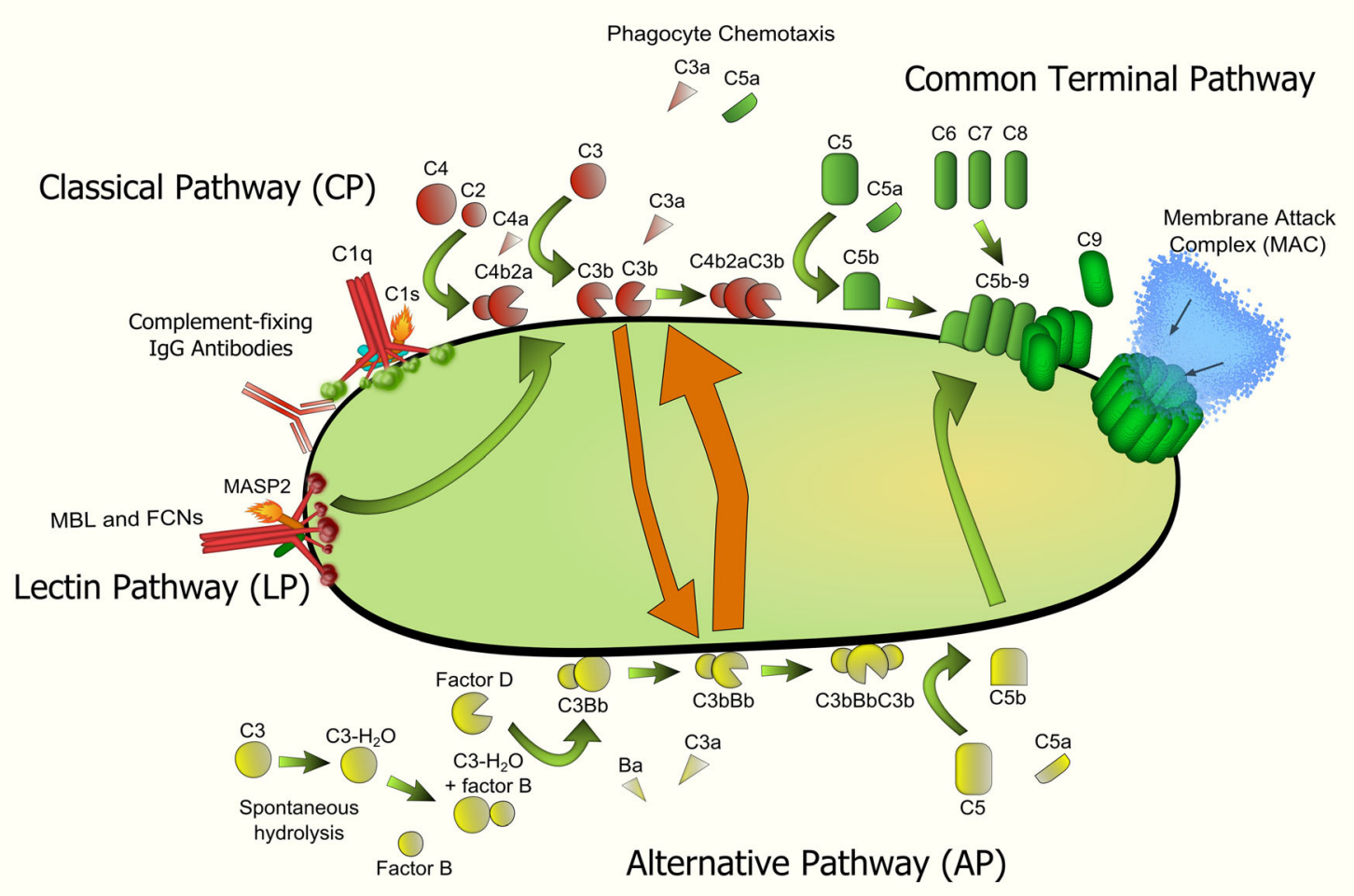

Fig. 2 Complement activation pathways. Complement activation is mainly initiated via the CP and LP of complement. Initiation of complement activation on the bacterial surface occurs via either $\mathrm{C} 1 \mathrm{q}$ of the $\mathrm{CP}$ or via mannose-binding lectin (MBL) or ficolins (FCNs) of the LP and is indicated in red. Complement-fixing IgG, bound to the surface of B. pertussis, activates the $\mathrm{CP}$ of complement. $\mathrm{C} 1 \mathrm{q}$, in complex with proteases $\mathrm{C} 1 \mathrm{r}$ and $\mathrm{C} 1 \mathrm{~s}$ binds to the bacterial surface and activates complement $\mathrm{C} 2$ and $\mathrm{C} 4$. Similarly, MBL and/or FCNs are in complex with serine protease MASP-1/-2/-3 (mannose-binding lectin-associated serine protease- $1 /-2 /-3$ ) and binding the pathogen surface leads to autoactivation of MASP-2, allowing cleavage of C2 and C4. C3 convertases can either cleave additional $\mathrm{C} 3$ into $\mathrm{C} 3 \mathrm{~b}$, or bind $\mathrm{C} 3 \mathrm{~b}$, producing the $\mathrm{C} 5$ convertase $(\mathrm{C} 4 \mathrm{bC} 2 \mathrm{aC} 3 \mathrm{~b})$. $\mathrm{C} 5$ convertases cleave $\mathrm{C} 5$ which in turn leads to the formation of the terminal pathway (indicated in green) which produces the membrane attack complex (MAC). The MAC is formed through the terminal assembly of complement components $\mathrm{C} 5 \mathrm{~b}$ through $\mathrm{C} 9$ and results in cell lysis and death of Gram-negative bacteria. The AP (indicated in yellow) involves the continuous spontaneous hydrolysis of $\mathrm{C} 3$ into $\mathrm{C} 3-\mathrm{HO}$, which binds to factor $\mathrm{B}$, producing $\mathrm{Bb}$ and $\mathrm{Ba}$ through the action of factor $\mathrm{D}$. Properdin binds and stabilizes the alternative $\mathrm{C} 3$ convertase $\mathrm{C} 3 \mathrm{bBb}$. The latter can either cleave more $\mathrm{C} 3$ or forms the $\mathrm{C} 5$ convertase by incorporation of another $\mathrm{C} 3 \mathrm{~b}$ molecule, producing the $\mathrm{C} 5$ convertase $(\mathrm{C} 3 \mathrm{bBbC} 3 \mathrm{~b})$. The AP can be activated spontaneously and it can also amplify the other pathways (as indicated with the orange arrows). In addition to MAC formation, activation of the complement cascade results in leukocyte chemotaxis and opsonization of the invading pathogen, leading to enhanced phagocytosis 
Th17 differentiation which has been reported to be important for protection against $B$. pertussis infections [24, 25]. Inhibition of complement activation by $B$. pertussis can therefore also have consequences for the induction of the T cells required for protection against this pathogen.

\section{Complement evasion strategies of $B$. pertussis}

In order to infect and survive in the human host, pathogens employ a broad range of strategies to escape recognition and killing by various immune mechanisms, including the complement system [10], and B. pertussis is no exception to this phenomenon. Although research on the interaction with $B$. pertussis and the innate immune system is limited, it is known that in order to escape the complement system, this bacterium expresses several complement evasion molecules. Unlike Bordetella parapertussis and Bordetella bronchiseptica, which can cause infectious bronchitis in humans [7], B. pertussis does not expresses lipopolysaccharide containing $\mathrm{O}$-antigen. Murine infection models show that lipopolysaccharide containing O-antigen facilitates colonization of the respiratory tract of mice and also plays an important role in the protection against complement-mediated killing
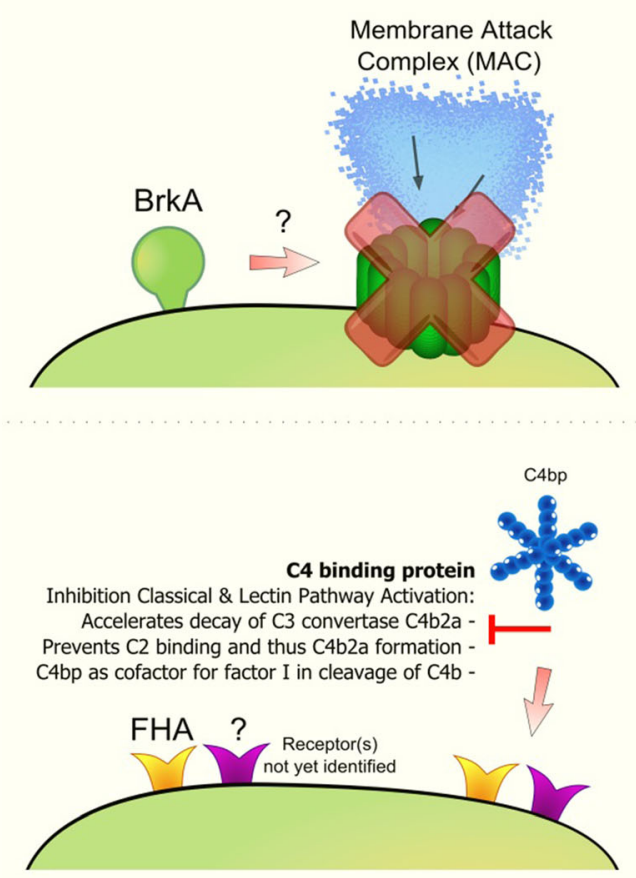

Fig. 3 Complement resistance mechanisms of B. pertussis. B. pertussis has evolved several strategies to evade complement activation. a BrkA, an autotransporter of $B$. pertussis, has been shown to be involved in complement evasion. The exact mechanism of how BrkA inhibits complement activation remains unknown. b B. pertussis binds $\mathrm{C} 1$-inh to the bacterial surface which increased resistance to complementmediated killing. The Vag8 protein of B. pertussis was identified as the since it prevents $\mathrm{C} 3 \mathrm{~b}$ deposition on the bacteria surface [26, 27]. In addition to O-antigen, other surface polysaccharides have also been shown to provide complement resistance [28, 29]. Like other bacterial pathogens, B. pertussis expresses a polysaccharide (Bps) which belongs to a large family of $\beta-(1-$ 6)-linked polymeric-N-acetylglucosamine (GlcNAc) polysaccharides. Bps polysaccharide was shown to be essential for early colonization of the respiratory tract of mice by B. pertussis [30, 31]. Recent studies show that Bps mutant strains are more sensitive to complement-mediated killing compared to the $B$. pertussis wild-type strain $[32,31]$. As mice are not the natural reservoir of $B$. pertussis and its pathology of infection is different from humans, further studies are needed to establish the effect of surface polysaccharides during infections in humans. In addition to surface polysaccharides, B. pertussis expresses several other proteins involved in complement evasion (Fig. 3) which are described in detail below.

The 103-kDa autotransporter, Bordetella resistance to killing $\mathrm{A}$ (BrkA) protein of B. pertussis promotes attachment to human cells and has also been shown to be involved in complement evasion [33] (Fig. 3a). Studies using a BrkA mutant and a BrkA overexpressing $B$. pertussis strain demonstrated that BrkA reduces $\mathrm{C} 4$ and $\mathrm{C} 3$ deposition on the bacterial surface and subsequently, the formation of the MAC complex
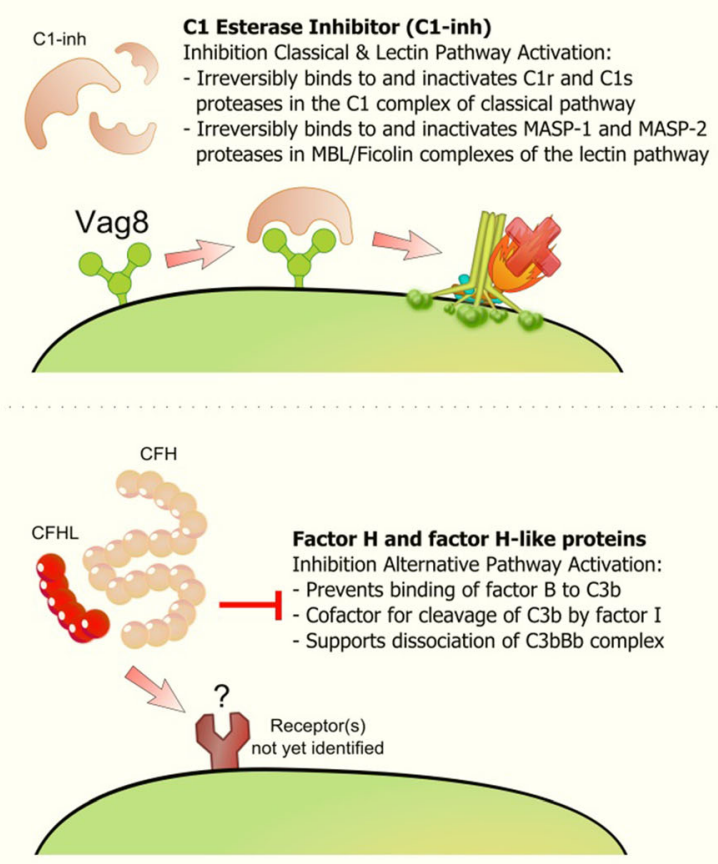

C1-inh binding factor. $\mathbf{c}$ B. pertussis binds C4BP via its surface protein FHA and possibly via one or more other receptors. Strains deficient in FHA were still able to bind C4BP, although strongly reduced. d $B$. pertussis isolates recruit host complement regulators that are part of the fH family such as complement $\mathrm{CFH}$, factor H-like 1 (CFHL), and factor H-related (CFHR) proteins by expressing one or more receptors that have not yet been identified 
[34]. Since C1q deposition was not altered by BrkA, the authors conclude that BrkA either promotes degradation of $\mathrm{C} 4 \mathrm{~b}$ on the bacterial surface or inhibits $\mathrm{C} 4$ activation [34]. The authors did not investigate a potential direct effect of BrkA on $\mathrm{C} 1, \mathrm{C} 2$, and/or C4. Direct binding of BrkA to those proteins could result in conformational changes of these proteins, thereby preventing their activation. Another possibility is inactivation of $\mathrm{C} 1, \mathrm{C} 2$, and/or $\mathrm{C} 4$ by BrkA via proteolytic cleavage. Furthermore, all studies were performed with whole bacteria rather than recombinant BrkA so it cannot be excluded that BrkA is indirectly involved in complement inhibition rather than directly. Therefore, the precise mechanism by which BrkA inhibits complement activation remains to be fully elucidated. Recent studies also identified another autotransporter protein, Bordetella autotransporter protein-C (BapC) that is involved in serum resistance. Although it was shown that a BapC mutant of $B$. pertussis is more susceptible to serum killing, the mechanism of action remains unidentified [35].

A frequently used mechanism by pathogens to evade complement-mediated killing is the acquisition of host complement regulators on their surfaces [10]. The host complement regulator $\mathrm{C} 1$ esterase inhibitor (C1-inh) belongs to the superfamily of serine protease inhibitors. $\mathrm{C} 1$-inh binds irreversibly to and inactivates both $\mathrm{C} 1 \mathrm{r}$ and $\mathrm{C} 1 \mathrm{~s}$ proteases of the $\mathrm{CP}$ and mannan-binding lectin-associated serine protease (MASP)-1 and MASP-2 of the LP [36]. B. pertussis, but not the related B. bronchiseptica, B. parapertussis, Bordetella holmesii, or Bordetella avium, recruits $\mathrm{C} 1$-inh to its bacterial surface to inhibit complement activity [37]. The binding of $\mathrm{C} 1$-inh to the bacterial surface is dependent on the expression of genes that are under control of the Bordetella master virulence regulatory locus (bvgAS) [37]. The BvgAS proteins form part of a two-component sensory transduction system which is regulated by environmental signals. Growth in the presence of sulfate, nicotinic acid, or low temperature results in lack of expression of the $b v g$-activated genes and results in an avirulent phenotype of this bacterium [38]. Using different growth conditions, the authors showed that $\mathrm{C} 1$-inh binding occurred only during the virulent phase. Recently, the passenger domain of the autotransporter Vag8 was identified as the C1-inh binding factor of B. pertussis. Importantly, Vag8 expression correlates with serum resistance [39] (Fig. 3b). Interestingly, the $B$. pertussis ptxP3 (or P3) lineage which has recently expanded globally, produces higher amounts of Vag8 than the strains it replaced [40]. In addition to $B$. pertussis, only one other pathogenic bacterium was shown to bind C1-inh. Escherichia coli strain 0157:H7 can bind C1inh to its surface via the metalloprotease StcE, to evade the complement system [41, 42].

The host complement regulator $\mathrm{C} 4 \mathrm{~b}$-binding protein (C4BP) also inhibits complement activation via the $\mathrm{CP}$ and LP. C4BP is a spider-like molecule of $570 \mathrm{kDa}$, composed of seven identical $\alpha$-chains and one $\beta$-chain held together by disulfide bridges. Both chains are composed of complement control protein domains (CCPs). $\mathrm{C} 4 \mathrm{BP}$ binds to $\mathrm{C} 4 \mathrm{~b}$, thereby dissociating the CP/LP C3 convertase $\mathrm{C} 4 \mathrm{~b} 2 \mathrm{a}$ and it acts as a cofactor for the plasma protease factor I in the proteolytic degradation of $\mathrm{C} 4 \mathrm{~b}[10]$. B. pertussis binds $\mathrm{C} 4 \mathrm{BP}$ via its surface protein filamentous hemagglutinin (FHA) [43] (Fig. 3c). Although C4BP binding to B. pertussis occurs under physiological conditions and $\mathrm{C} 4 \mathrm{BP}$ retains its complement regulatory activity when surface-bound [44], protection from complement-mediated lysis has not been proven. $B$. pertussis mutants that do not express FHA have a similar sensitivity toward complement compared to the wild-type strain [45]. Studies using C4BP mutants show that $B$. pertussis binds $\mathrm{C} 4 \mathrm{BP}$ at the CCP1-2 domain interface of the $\alpha$-chain. Amino acids R64 and R66 of C4BP are the major players in the binding site. Moreover, studies with $\mathrm{mAb}$ directed towards the $\mathrm{C} 4 \mathrm{BP} \alpha$-chain indicate that $B$. pertussis binds $\mathrm{C} 4 \mathrm{BP}$ at a site similar to the C4b-binding site [44]. Although strongly reduced, fha mutants were still able to bind C4BP. $b v g$ mutants failed to bind C4BP [43] indicating that besides FHA, one or more BvgAS-regulated proteins contribute to the binding of C4BP (Fig. 2b). Binding of C4BP to bacterial pathogens is a common phenomenon. Neisseria meningitidis binds C4BP via its type IV Pili [46], group A streptococcus binds C4BP via the M-protein family member Sir and Arp [47, 48] and also $E$. coli strain $\mathrm{K} 1$ binds $\mathrm{C} 4 \mathrm{BP}$ via outer membrane protein A [49].

Finally, B. pertussis and B. parapertussis are both capable of binding host-derived negative complement regulator $\mathrm{fH}$ family proteins including factor H-like (FHL)-1 and factor H-related (FHR)-1. Binding of fH family proteins by pathogens contributes to their survival in human serum [50] (Fig. 3d). FH, the main negative regulator of the AP, consists of 20 short consensus repeat (SCR) domains and recent studies show that $B$. pertussis binds $\mathrm{fH}$ via SCR20 and SCR5-7 $[51,50]$. FH binding by other pathogenic bacteria such as Pseudomonas aeruginosa, Haemophilus influenza, and Streptococcus pneumoniae occurs via SCR19-20 through a common site in SCR20 named the "common microbial binding site." This binding site allows the formation of a tripartite microbial protein: $\mathrm{fH}: \mathrm{C} 3 \mathrm{~b}$ complex which enhances $\mathrm{fH}$ mediated inactivation of $\mathrm{C} 3 \mathrm{~b}$. A similar mechanism of complement evasion has not yet been shown for $B$. pertussis [51] since the $\mathrm{fH}$ binding protein(s) of $B$. pertussis remains unidentified. Ptx could be involved in $\mathrm{fH}$ binding since an isogenic strain of Tohama I, lacking Ptx, is more sensitive to serum killing via the AP than the parental strain [50]. Taken together, $B$. pertussis produces various complement evasion molecules to successfully colonize and persist in the human host. We hypothesize that $B$. pertussis expresses more, yet unidentified, molecules for regulating complement activation since other well studied bacteria have proven to express at least a dozen. 


\section{Complement evasion molecules and vaccine development}

The recent increase in pertussis cases worldwide has made it clear that further research on the pathogenesis and immunity of $B$. pertussis is required for the development of a new generation of vaccines. Besides humans, no other reservoirs for $B$. pertussis have been described. Therefore, strain adaptation is driven by the human immune system only and waning immunity may accelerate this process by allowing a high circulation rate of the pathogen [52]. Next-generation B. pertussis vaccines should include antigen preparations that induce long-lasting immunity and strengthens the innate immune system. Strengthening innate immune responses will result in elimination of $B$. pertussis immediately after exposure to this bacterium, preventing transmission and thereby, opportunities for strain adaptation.

New-generation vaccines against a number of pathogens are currently converging on the use of complement evasion molecules as vaccine targets. The best example is factor $\mathrm{H}$ binding protein (fHbp) of $N$. meningitidis, which is the leading antigen in vaccine development against $N$. meningitidis serogroup B [53]. fHbp binds to $\mathrm{fH}$ providing an important mechanism for immune evasion by inhibition of the complement system [54, 55]. Next to the vaccine against $N$. meningitidis, other vaccines containing complement evasion molecules are also investigated $[56,57]$. BibA is a virulent factor from group B Streptococcus that is able to bind to C4BP and promotes adhesion of group B streptococcus to human epithelial cells [58]. Recent studies also indicate pneumococcal proteins PspA and $\mathrm{PspC}$ as potential vaccine candidates. PspA and PspC are important virulence factors expressed by almost all pneumococcal strains. Both proteins are known as complement evasion molecules. PspA interferes with complement deposition on the bacterial surface and PspC binds to $\mathrm{fH}[59,60]$.

The aP vaccine for B. pertussis consists of Ptx, Fim, FHA, and Prn (depending on which country). As described above in detail, FHA is a known C4BP-binding molecule [43, 44]. Recent studies show that vaccination with Vag8, the C1-inh binding protein of $B$. pertussis, results in a protective immune response against $B$. pertussis in mice [52]. All these data together underline the promising perspective of using complement modulating proteins in new vaccines.

Studies to identify additional molecules involved in complement evasion by $B$. pertussis are needed to develop new and improved vaccines against $B$. pertussis. Vaccines containing $B$. pertussis complement evasion molecules will prevent complement escape and complement downregulation. Effective activation of the complement system is important since the function of the complement system goes beyond protecting the host from infection by immediate elimination of pathogens; it is also involved in modulation of adaptive immune responses [14]. Altogether, it is of crucial importance to unravel the complement evasion strategies of $B$. pertussis in order to improve the existing vaccines against pertussis.

\section{Concluding remarks}

Despite high vaccination coverage, reported cases of pertussis are rising which clearly indicates the urgency for a more effective vaccine [9]. The role of the complement system in protection against $B$. pertussis has only recently become apparent $[25,61]$, and research on complement evasion by $B$. pertussis is limited. We propose that improved pertussis vaccines should contain antigen preparations that, in addition to inducing long-lasting immunity, can prevent suppression of the innate immune response by $B$. pertussis. One of the possibilities is inclusion of complement evasion molecules in current aP vaccines. Neutralizing complement evasion molecules would allow more efficient activation of the complement system upon exposure to $B$. pertussis, which will result in faster eradication of the bacteria and potentially leads to a better activation of the adaptive immunity. In conclusion, complement evasion molecules are undoubtedly promising vaccine candidates.

Acknowledgments The RIVM SOR-000083 grant supported this research.

Open Access This article is distributed under the terms of the Creative Commons Attribution License which permits any use, distribution, and reproduction in any medium, provided the original author(s) and the source are credited.

\section{References}

1. Warfel JM, Beren J, Merkel TJ (2012) Airborne transmission of Bordetella pertussis. J Infect Dis 206(6):902-906

2. Mattoo S, Cherry JD (2005) Molecular pathogenesis, epidemiology, and clinical manifestations of respiratory infections due to Bordetella pertussis and other Bordetella subspecies. Clin Microbiol Rev 18(2): 326-382

3. Weiss AA, Hewlett EL (1986) Virulence factors of Bordetella pertussis. Annu Rev Microbiol 40:661-686

4. Paddock CD, Sanden GN, Cherry JD, Gal AA, Langston C, Tatti KM, Wu KH, Goldsmith CS, Greer PW, Montague JL et al (2008) Pathology and pathogenesis of fatal Bordetella pertussis infection in infants. Clin Infect Dis Off Publ Infec Dis Soc Am 47(3):328-338

5. Cherry JD (2013) Pertussis: challenges today and for the future. PLoS Pathog 9(7):e1003418

6. Mooi FR, NA VDM, De Melker HE (2013) Pertussis resurgence: waning immunity and pathogen adaptation - two sides of the same coin. Epidemiol Infect 142(4):685-694

7. van der Ark AA, Hozbor DF, Boog CJ, Metz B, van den Dobbelsteen GP, van Els CA (2012) Resurgence of pertussis calls for re-evaluation of pertussis animal models. Expert Rev Vaccines 11(9):1121-1137

8. He Q, Mertsola J (2008) Factors contributing to pertussis resurgence. Future Microbiol 3(3):329-339

9. Cherry JD (2012) Epidemic pertussis in 2012 - the resurgence of a vaccine-preventable disease. N Engl J Med 367(9):785-787

10. Zipfel PF, Hallstrom T, Riesbeck K (2013) Human complement control and complement evasion by pathogenic microbes - tipping the balance. Mol Immunol 56(3):152-160 
11. Walport MJ (2001) Complement. Second of two parts. N Engl J Med 344(15):1140-1144

12. Walport MJ (2001) Complement. First of two parts. N Engl J Med 344(14):1058-1066

13. Muller-Eberhard HJ (1986) The membrane attack complex of complement. Annu Rev Immunol 4:503-528

14. Ricklin D, Hajishengallis G, Yang K, Lambris JD (2010) Complement: a key system for immune surveillance and homeostasis. Nat Immunol 11(9):785-797

15. Kolev M, Le Friec G, Kemper C (2014) Complement-tapping into new sites and effector systems. Nat Rev Immunol 14(12):811-820

16. Bjornson AB, Mellencamp MA, Schiff GM (1991) Complement is activated in the upper respiratory tract during influenza virus infection. Am Rev Respir Dis 143(5 Pt 1):1062-1066

17. Persson CG, Erjefalt I, Alkner U, Baumgarten C, Greiff L, Gustafsson B, Luts A, Pipkorn U, Sundler F, Svensson C et al (1991) Plasma exudation as a first line respiratory mucosal defence. Clin Exp Allergy J Br Soc Allergy Clin Immunol 21(1):17-24

18. Watford WT, Ghio AJ, Wright JR (2000) Complement-mediated host defense in the lung. Am J Physiol Lung Cell Mol Physiol 279(5): L790-L798

19. Carroll MC, Isenman DE (2012) Regulation of humoral immunity by complement. Immunity 37(2):199-207

20. Kemper C, Kohl J (2013) Novel roles for complement receptors in T cell regulation and beyond. Mol Immunol 56(3):181-190

21. Kemper C, Atkinson JP (2007) T-cell regulation: with complements from innate immunity. Nat Rev Immunol 7(1):9-18

22. Zhou W (2012) The new face of anaphylatoxins in immune regulation. Immunobiology 217(2):225-234

23. Kolev M, Le Friec G, Kemper C (2013) The role of complement in CD4(+) T cell homeostasis and effector functions. Semin Immunol 25(1):12-19

24. Fang C, Zhang X, Miwa T, Song WC (2009) Complement promotes the development of inflammatory T-helper 17 cells through synergistic interaction with Toll-like receptor signaling and interleukin- 6 production. Blood 114(5):1005-1015

25. Higgs R, Higgins SC, Ross PJ, Mills KH (2012) Immunity to the respiratory pathogen Bordetella pertussis. Mucosal Immunol 5(5): 485-500

26. Goebel EM, Wolfe DN, Elder K, Stibitz S, Harvill ET (2008) O antigen protects Bordetella parapertussis from complement. Infect Immun 76(4):1774-1780

27. Burns VC, Pishko EJ, Preston A, Maskell DJ, Harvill ET (2003) Role of Bordetella $\mathrm{O}$ antigen in respiratory tract infection. Infect Immun 71(1):86-94

28. Kugelberg E, Gollan B, Tang CM (2008) Mechanisms in Neisseria meningitidis for resistance against complement-mediated killing. Vaccine 26(Suppl 8):I34-I39

29. Loh E, Kugelberg E, Tracy A, Zhang Q, Gollan B, Ewles H, Chalmers R, Pelicic V, Tang CM (2013) Temperature triggers immune evasion by Neisseria meningitidis. Nature 502(7470):237-240

30. Conover MS, Sloan GP, Love CF, Sukumar N, Deora R (2010) The Bps polysaccharide of Bordetella pertussis promotes colonization and biofilm formation in the nose by functioning as an adhesin. Mol Microbiol 77(6):1439-1455

31. Geurtsen J, Fae KC, van den Dobbelsteen GP (2014) Importance of (antibody-dependent) complement-mediated serum killing in protection against Bordetella pertussis. Expert Rev Vaccines 13(10):1229-1240

32. Ganguly T, Johnson JB, Kock ND, Parks GD, Deora R (2014) The Bordetella pertussis Bps polysaccharide enhances lung colonization by conferring protection from complement-mediated killing. Cell Microbiol 16(7):1105-1118

33. Fernandez RC, Weiss AA (1994) Cloning and sequencing of a Bordetella pertussis serum resistance locus. Infect Immun 62(11): $4727-4738$
34. Barnes MG, Weiss AA (2001) BrkA protein of Bordetella pertussis inhibits the classical pathway of complement after $\mathrm{C} 1$ deposition. Infect Immun 69(5):3067-3072

35. Noofeli M, Bokhari H, Blackburn P, Roberts M, Coote JG, Parton R (2011) BapC autotransporter protein is a virulence determinant of Bordetella pertussis. Microb Pathog 51(3):169-177

36. Zeerleder S (2011) C1-inhibitor: more than a serine protease inhibitor. Semin Thromb Hemost 37(4):362-374

37. Marr N, Luu RA, Fernandez RC (2007) Bordetella pertussis binds human $\mathrm{C} 1$ esterase inhibitor during the virulent phase, to evade complement-mediated killing. J Infect Dis 195(4):585-588

38. Arico B, Miller JF, Roy C, Stibitz S, Monack D, Falkow S, Gross R, Rappuoli R (1989) Sequences required for expression of Bordetella pertussis virulence factors share homology with prokaryotic signal transduction proteins. Proc Natl Acad Sci U S A 86(17):6671-6675

39. Marr N, Shah NR, Lee R, Kim EJ, Fernandez RC (2011) Bordetella pertussis autotransporter Vag8 binds human $\mathrm{C} 1$ esterase inhibitor and confers serum resistance. PLoS One 6(6):e20585

40. Mooi FR, van Loo IH, van Gent M, He Q, Bart MJ, Heuvelman KJ, de Greeff SC, Diavatopoulos D, Teunis P, Nagelkerke N et al (2009) Bordetella pertussis strains with increased toxin production associated with pertussis resurgence. Emerg Infect Dis 15(8):1206-1213

41. Lathem WW, Bergsbaken T, Welch RA (2004) Potentiation of C1 esterase inhibitor by StcE, a metalloprotease secreted by Escherichia coli O157:H7. J Exp Med 199(8):1077-1087

42. Lathem WW, Grys TE, Witowski SE, Torres AG, Kaper JB, Tarr PI, Welch RA (2002) StcE, a metalloprotease secreted by Escherichia coli $\mathrm{O} 157: \mathrm{H7}$, specifically cleaves $\mathrm{C} 1$ esterase inhibitor. Mol Microbiol 45(2):277-288

43. Berggard K, Johnsson E, Mooi FR, Lindahl G (1997) Bordetella pertussis binds the human complement regulator C4BP: role of filamentous hemagglutinin. Infect Immun 65(9):3638-3643

44. Berggard K, Lindahl G, Dahlback B, Blom AM (2001) Bordetella pertussis binds to human $\mathrm{C} 4 \mathrm{~b}$-binding protein $(\mathrm{C} 4 \mathrm{BP})$ at a site similar to that used by the natural ligand C4b. Eur J Immunol 31(9):27712780

45. Fernandez RC, Weiss AA (1998) Serum resistance in bvg-regulated mutants of Bordetella pertussis. FEMS Microbiol Lett 163(1):57-63

46. Schneider MC, Exley RM, Ram S, Sim RB, Tang CM (2007) Interactions between Neisseria meningitidis and the complement system. Trends Microbiol 15(5):233-240

47. Jarva H, Jokiranta TS, Wurzner R, Meri S (2003) Complement resistance mechanisms of streptococci. Mol Immunol 40(2-4):95-107

48. Thern A, Stenberg L, Dahlback B, Lindahl G (1995) Ig-binding surface proteins of Streptococcus pyogenes also bind human $\mathrm{C} 4 \mathrm{~b}$ binding protein (C4BP), a regulatory component of the complement system. J Immunol 154(1):375-386

49. Wooster DG, Maruvada R, Blom AM, Prasadarao NV (2006) Logarithmic phase Escherichia coli K1 efficiently avoids serum killing by promoting $\mathrm{C} 4 \mathrm{bp}$-mediated $\mathrm{C} 3 \mathrm{~b}$ and $\mathrm{C} 4 \mathrm{~b}$ degradation. Immunology 117(4):482-493

50. Amdahl H, Jarva H, Haanpera M, Mertsola J, He Q, Jokiranta TS, Meri S (2011) Interactions between Bordetella pertussis and the complement inhibitor factor H. Mol Immunol 48(4):697-705

51. Meri T, Amdahl H, Lehtinen MJ, Hyvarinen S, McDowell JV, Bhattacharjee A, Meri S, Marconi R, Goldman A, Jokiranta TS (2013) Microbes bind complement inhibitor factor $\mathrm{H}$ via a common site. PLoS Pathog 9(4):e1003308

52. Gouw D, Jonge MI, Hermans PW, Wessels HJ, Zomer A, Berends A, Pratt C, Berbers GA, Mooi FR, Diavatopoulos DA (2014) Proteomics-identified Bvg-activated autotransporters protect against Bordetella pertussis in a mouse model. PLoS One 9(8):e105011

53. Santolaya ME, O'Ryan ML, Valenzuela MT, Prado V, Vergara R, Munoz A, Toneatto D, Grana G, Wang H, Clemens R et al (2012) Immunogenicity and tolerability of a multicomponent meningococcal serogroup B (4CMenB) vaccine in healthy adolescents in Chile: a 
phase $2 \mathrm{~b} / 3$ randomised, observer-blind, placebo-controlled study. Lancet 379(9816):617-624

54. Schneider MC, Exley RM, Chan H, Feavers I, Kang YH, Sim RB, Tang CM (2006) Functional significance of factor $\mathrm{H}$ binding to Neisseria meningitidis. J Immunol 176(12):7566-7575

55. Madico G, Welsch JA, Lewis LA, McNaughton A, Perlman DH, Costello CE, Ngampasutadol J, Vogel U, Granoff DM, Ram S (2006) The meningococcal vaccine candidate GNA1870 binds the complement regulatory protein factor $\mathrm{H}$ and enhances serum resistance. J Immunol 177(1):501-510

56. Serruto D, Rappuoli R, Scarselli M, Gros P, van Strijp JA (2010) Molecular mechanisms of complement evasion: learning from staphylococci and meningococci. Nat Rev Microbiol 8(6):393-399

57. Meri S, Jordens M, Jarva H (2008) Microbial complement inhibitors as vaccines. Vaccine 26(Suppl 8):I113-I117
58. Santi I, Maione D, Galeotti CL, Grandi G, Telford JL, Soriani M (2009) BibA induces opsonizing antibodies conferring in vivo protection against group B Streptococcus. J Infect Dis 200(4):564-570

59. Schachern PA, Tsuprun V, Ferrieri P, Briles DE, Goetz S, Cureoglu S, Paparella MM, Juhn S (2014) Pneumococcal PspA and PspC proteins: potential vaccine candidates for experimental otitis media. Int $\mathrm{J}$ Pediatr Otorhinolaryngol 78(9):1517-1521

60. Katsura H, Piao Z, Iwatsuki-Horimoto K, Akeda Y, Watanabe S, Horimoto T, Oishi K, Kawaoka Y (2014) A bivalent vaccine based on a replication-incompetent influenza virus protects against Streptococcus pneumoniae and influenza virus infection. J Virol 88(22):13410-13417

61. Grondahl-Yli-Hannuksela K, Viander M, Mertsola J, He Q (2013) Increased risk of pertussis in adult patients with mannose-binding lectin deficiency. APMIS Acta Pathol Microbiol Immunol Scand 121(4):311-315 